\title{
Effect of household storage practices on iodine content of iodized salt
}

\section{RASHMI SINGH AND R.S. RAGHUVANSHI}

Received: 12.07.2014; Revised: 12.10.2014; Accepted: 25.10 .2014

See end of the paper for authors' affiliations RASHMI SINGH

Department of Food Science and Nutrition, College of Home Science, C. S.A. University of Agriculture and Technology, KANPUR (U.P.) INDIA

Email: rashmi_csau@yahoo.co.in
ABSTRACT : Iodine deficiency is amongst the most widely prevalent nutritional problems of Indian peninsula. India is one of the major iodine deficient countries in the world. Iodine deficiency is the most common cause of preventable mental retardation and brain damage. It causes goitre and decreases the production of hormones vital to growth and development. In India it is estimated that about 200 million people are at risk for iodine deficiency disorders. Iodized salt is undoubtedly the strategy for the country still iodine is not fully utilized by the people because of improper handling, usage and storage practices and the data regarding its losses in iodized salt during storage at household level are not available. Keeping the above facts in consideration, the present study was planned with the objective to determine the effect of storage place, duration, type of storage vessel on the iodine content of the salt.

KEY WORDS: Iodine, Iodized salt, Iodine deficiency disorder (IDD), Iodine loss, Storage practices

口 HOW TO CITE THIS PAPER : Singh, Rashmi and Raghuvanshi, R.S. (2014). Effect of household storage practices on iodine content of iodized salt. Asian J. Home Sci., 9 (2) : 481-483. 